\title{
New Immunotherapies in Oncology Treatment and Their Side Effect Profiles
}

Pramern Sriratana, MD, and Joseph Norton, BS, DO

Background: Immunotherapies in cancer treatment have a long history going all the way back to the very beginning of the field, and recent advances are extremely promising. These therapies are becoming a larger part in many patients' oncology treatment as the number of approaches, individual medicines, and indications increase. Furthermore, these novel therapies have different side effect profiles from those traditional chemotherapies which have, until recently, typified the oncologist's approach to treatment together with surgery and radiation.

Methods: An electronic literature search was conducted in May and June 2017 and March 2018 with the PubMed and Ebscohost databases. Articles were chosen for their relevance to the drugs in question, cancer physiology, or historic significance.

Conclusions: Checkpoint inhibitors are becoming very common and possess autoimmune side effects such as pneumonitis, hypothyroidism, and colitis. These may present at any time the patient is on the medications but are more common several weeks to several months from beginning therapy. Chimeric antigen receptor T-cell therapies are powerful but have strong side effects such as cytokine release syndrome. Neoantigens are currently in the early stages of clinical trials and may become an exciting avenue for personalized cancer treatment but are not yet typical. (J Am Board Fam Med 2018;31: 620-627.)

Keywords: Antigen Receptors, Cancer, Immunotherapy, Oncologists

Immunotherapies are becoming a larger part in many patients' oncology treatment as the number of approaches, individual medicines, and indications increase. Furthermore, these novel therapies have different side effect profiles from those traditional chemotherapies which have, until recently, typified the oncologist's approach to treatment together with surgery and radiation. Thus, it is imperative that family physicians seek out and recognize the possible toxicities of these new treatments with as great a proficiency as they have for more

This article was externally peer reviewed.

Submitted 26 September 2017; revised 20 March 2018; accepted 25 March 2018.

From Mid-Illinois Hematology and Oncology Associations, Normal, IL (PS); Kirksville College of Osteopathic Medicine, Kirksville, MO (JN).

Funding: none.

Conflict of interest: none declared.

Corresponding author: Joseph Norton, BS, DO, 1005 Arlene ct apt 4, Bloomington, IL 61701 (E-mail: janorton@ atsu.edu). traditional therapies to better care for their patients.

\section{Methods}

In May and June 2017, the literature search was conducted. Sources composed of 2015 to May 2017 issues of the Journal of Clinical Oncology, Journal of the National Comprehensive Cancer Network, The Lancet Oncology, as well as materials published from the Institute for Clinical Immuno-Oncology and the Dana-Farber Cancer Institute. Prescribing information published by Genetech, Bristol-Meyers Squibb, and Merck for atezolizumab, nivolumab, and pembrolizumab, respectively, were also reviewed in June 2017. The electronic literature search was conducted with the PubMed and Ebscohost databases. Articles were chosen for their relevance to the drugs in question, cancer physiology, or historic significance. Search terms included were: immuno-oncology, Coley's toxin, cancer immunotherapy, checkpoint inhibitors, CTLA-4, PD-1, PDL-1, CAR-T-cell, chi- 
meric antigen receptor $\mathrm{T}$ cell, neoantigens, and tumor specific mutant antigens. Follow-up searches were performed using the same databases in March 2018 for the terms toxicities and checkpoint inhibitors.

\section{Background}

\section{Brief History of Immunotherapy}

Harnessing the immune system to battle cancer has a long history going back to $2600 \mathrm{BC}$ when the pharaoh Imhotep created an infection in himself to facilitate tumor regression. ${ }^{1}$ Within modern medicine, the mention of an interrelation between cancer and the immune system dates to the 18th century, when it was noted that patients with a febrile illness often had a coincidental cancer response. $^{2}$ This culminated in 1893, when Dr. William Coley noted a tumor response in patients treated with streptococcal species and created his famous Coley's toxin to use the effect. ${ }^{2,3}$

In 1949, Sir Frank Macfarlane Burnet published his theory of acquired immunity, leading researchers to postulate the existence of a tumor-associated antigen that could be directly targeted. ${ }^{4,5}$ This approach underlies several successful antineoplastic drugs today, such as trastuzumab, which treats HER-2(+) cancers, as well as novel approaches using neoantigens. ${ }^{6}$

Another innovation came in 1969, when Dr. Burnet proposed the immunosurveillance model of immunity. ${ }^{7}$ This states that lymphocytes eliminate malignant cells in addition to their previously known tasks against foreign substances, which was confirmed with the discovery of the programmed death receptor (PD-1), cytotoxic T-lymphocyteassociated protein 4 (CTLA-4), and other cell death and immune checkpoint proteins. ${ }^{4,7-9}$ Many of the new drugs and treatment strategies derive from these receptors and ligands, whereas others use the immunosurveillance model itself, such as the chimeric antigen receptor (CAR) T-cell therapies.

The use of cancer vaccines, such as the lauded human papillomavirus vaccine, and monoclonal antibodies, such as trastuzumab, have become commonplace in the oncology world. Their side effect profiles are well understood throughout the medical community. However, several newer advances such as the checkpoint-inhibitors, CAR T-cells, and neoantigen therapies are less known therapies and their profiles are largely unknown outside of the oncology community.

\section{Checkpoint Inbibitors}

T-cells express the T-cell receptor (TCR), which binds to the major histocompatibility complex (MHC), and will either activate or deactivate the T-cell, depending on either costimulatory or coinhibitory input from other ligands. ${ }^{10}$ The protein cluster of differentiation 28 (CD28) causes T-cell activation via a costimulatory pathway. ${ }^{11}$ Notable coinhibitory pathways include the programmed death receptor and ligand pathway (PD-L1), and the CTLA-4 pathway. ${ }^{9,11}$ These pathways are vital for proper immune system function, as too much inhibition causes inappropriate inactivation of $\mathrm{T}$ cells, whereas too much activation causes inappropriate activation. Figure 1 provides a visual model of the T-cell activation/deactivation pathways described above.

Malignancies can derange these pathways. Sezary syndrome and other T-cell lymphomas upregulate the production of CTLA-4, a pathway inhibitor, and thus avoid destruction via T-cells. ${ }^{12-14}$ The other pathways have a similar disregulation. Epstein-Barr virus-associated malignancies upregulate PD-L1 and several cancers, such as Hodgkin's lymphoma, produce an aberrant, stable form of the PD-L1 to increase the inhibitory signal, and evade the immune system. ${ }^{15-17}$ Piercing the inhibitory effect of unduly upregulated CTLA-4 and PD-L1 would allow the native immune system to attack these neoplasms, thus affording pathways for antineoplastic drugs.

Drugs approved by the Food and Drug Administration currently exist that target CTLA-4 (ipilimumab) and PD-L1 (nivolumab, pembrolizumab, avelumab, and atezolizumab). ${ }^{18-22}$ The indications for these drugs continue to grow at an extreme pace. Approval for this class of medication has been given for treatment of melanoma, nonsmall cell lung carcinoma, renal cell carcinoma, squamous cell carcinoma of the head and neck, urothelial carcinoma, Hodgkin's lymphoma, microsatellite instability-high cancers of any origin, hepatocellular carcinoma, and Merkel cell carcinoma. ${ }^{18-23}$ Most of these indications are for specific subsets of these tumors, especially secondary to other Food and Drug Administration-approved treatments; however, some indications are first-line, such as pembrolizumab's treatment for certain cases of 
Figure 1. Visual Model of Cytotoxic T-Lymphocyte-Associated Protein 4 (CTLA-4) and Programmed Death Ligand 1 (PD-L1) Action. TCR, T-cell receptor; MHC, major histocompatibility complex; CD28, cluster of differentiation 28; CD80, cluster of differentiation 80.

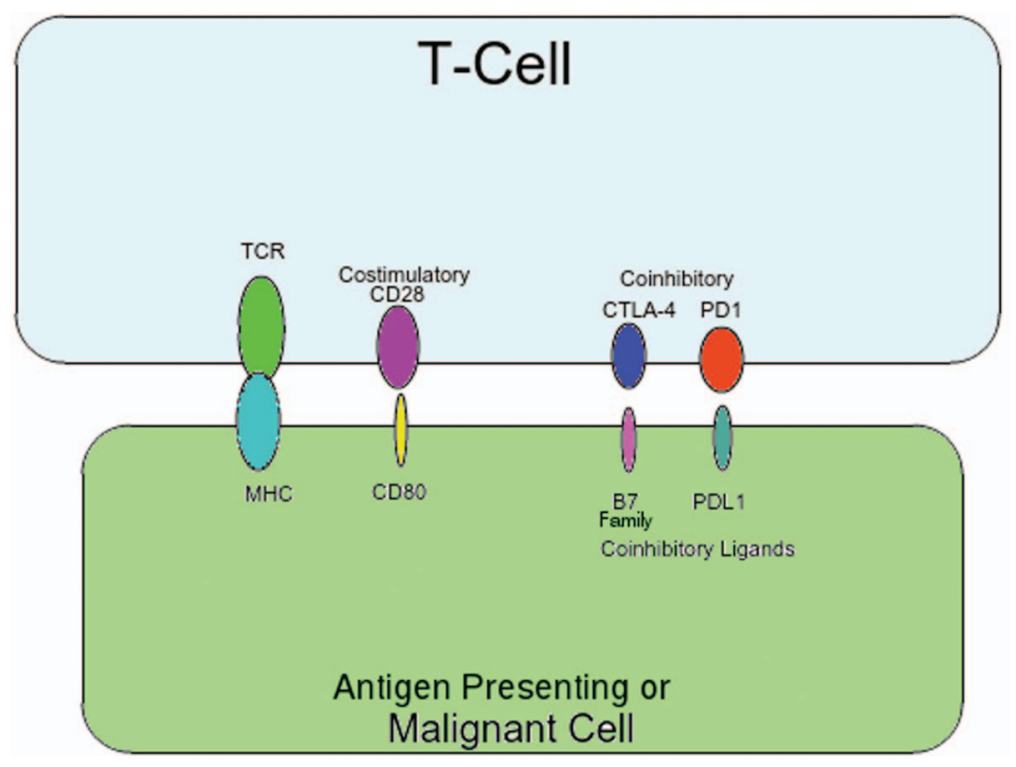

metastatic nonsmall cell lung carcinoma. ${ }^{18-23}$ This list is much larger compared to a few years ago, and more are becoming first-line. In fact, avelumab was quite recently approved for its current indication for Merkel cell carcinoma. ${ }^{22}$ This further demonstrates the rapid pace of these developments.

As the list of indications for these drugs increases, it stands to reason that more patients will receive them as a part of their treatment. They are the most common class of drug discussed at length in this article and likely will play a substantial role in future oncology treatments. As such, family physicians should be versed in their side effect profiles to recognize complications as they arise. The most common side effects for all these medications are mild and include fatigue, nausea, and decreased appetite. ${ }^{18-22}$ Although most of side effects noted above are common to many drugs, the more severe side effects specific to the checkpoint inhibitors may be easily remembered, as they are most likely secondary to their immunologic mechanisms. They not infrequently seem in combination, and sometimes in sequence. ${ }^{24}$ Important side effects, mentioned here to demonstrate the overall drug's category profile, include immunemediated colitis, pneumonitis, hepatitis, endocrinopathies such as hypothyroidism, and, rarely, encephalitis. Immune-mediated pneumonitis occurred in $1.2 \%-3.4 \%$ of patients studied in patients on a
PD-L1 target drug. ${ }^{19-22}$ Grade 3 to 4 immune-mediated hepatitis occurred in $0.7 \%-11 \%$ in patients studied that were using either CTLA-4 or PD-L1 targeting drugs. ${ }^{18-22}$ Further highlighting the clinical importance of the immune-mediated side effects, a study showed that $8 \%$ of patients treated with pembrolizumab required treatment discontinuation and prednisone therapy for moderate to severe side effects. ${ }^{20}$ Although these percentages are only examples, they present a picture of the commonality and severity of these side effects. Further data are shown in Table 1.

The onset time for these side effects are highly variable and are affected by drug, regimen, additional treatments, and the side effect itself. ${ }^{18-22}$ Take immune-mediated colitis for example: the median onset for immune-mediated colitis in a patient with single-agent nivolumab was 5.3 months, but the earliest reported was 2 days from the beginning of therapy and the latest was 20.9 months. ${ }^{19}$ Likewise for pembrolizumab, the median time to onset was 3.5 months for immunemediated colitis but varied from 10 days to 16.2 months. ${ }^{20}$ For ipilimumab in the adjuvant treatment of melanoma, onset for immune-mediated colitis was 1.1 month but varied from 1 day to 20.6 months. ${ }^{18}$ One can see the degree of variation. Whereas if one were to look at a single drug and regimen but the various side-effects it can be noted 
Table 1. Immune-Mediated Side Effects of Programmed Death Ligand Inhibitors ${ }^{19-22}$

\begin{tabular}{lcccccccc}
\hline & $\begin{array}{c}\text { Immune-Mediated } \\
\text { Drug }\end{array}$ & & & $\begin{array}{c}\text { Adrenal } \\
\text { Side Effect Colitis }\end{array}$ & $\begin{array}{c}\text { Thyroid } \\
\text { Pneumonitis }\end{array}$ & Hepatitis & Diabetes & $\begin{array}{c}\text { Renal } \\
\text { Insufficiency }\end{array}$ \\
\hline Dysfunction & Hypophysitis & $\begin{array}{c}\text { Mellitus 1 } \\
\text { Dysfunction }\end{array}$ \\
Pembrolizumab & $1.7 \%$ & $3.4 \%$ & $0.7 \%$ & $0.0 \%$ & $12.5 \%$ & $0.6 \%$ & $0.2 \%$ & $0.3 \%$ \\
Atezolizumab & $19.7 \%$ & $2.6 \%$ & $2.3 \%$ & $0.4 \%$ & $4.9 \%$ & $0.2 \%$ & $0.2 \%$ & $0.0 \%$ \\
Nivolumab & $2.9 \%$ & $3.1 \%$ & $1.8 \%$ & $1.0 \%$ & $11.7 \%$ & $0.6 \%$ & $0.9 \%$ & $1.2 \%$ \\
Avelumab & $1.5 \%$ & $1.2 \%$ & $0.9 \%$ & $0.5 \%$ & $6.0 \%$ & $0.0 \%$ & $0.1 \%$ & $0.1 \%$ \\
\hline
\end{tabular}

the average onset of each is slightly different, but an overall time frame becomes apparent. ${ }^{19}$ Table 2 demonstrates this for nivolumab as a single agent, for a representative picture of side effects through time. Note that the mean time to onset for all these side effects is on the scale of months. ${ }^{19}$ Therefore, the family physician should be cognizant of these side effects whenever their patient is on these medications but especially several weeks to months into therapy.

Some patients may be at higher risk of side effects than others. Studies involving checkpoint inhibitors have excluded patients with autoimmune disorders and chronic infections due to the drugs' mechanism of action, and, therefore, the exact risks to these patients is unknown. ${ }^{25}$ However, a retrospective study with ipilimumab demonstrates a slightly higher incidence of severe, immune-mediated side effects for those with a pre-existing autoimmune disorder than in the general population, at $33 \%$ versus $25 \%$ of immune-mediated side effects. ${ }^{26,27}$ In addition, $38 \%$ of patients with a preexisting autoimmune disorder experienced a flair up of it while on ipilimumab; however, most were considered mild. ${ }^{28}$ For patients with chronic infections, the theory, several case series, a retrospective

Table 2. Side Effects of Nivolumab as a Single Agent by Mean Time to Onset ${ }^{19}$

\begin{tabular}{lc}
\hline Nivolumab Side Effect & Mean Time to Onset, Months \\
\hline Hyperthyroidism & 1.5 \\
Rash & 2.8 \\
Hypothyroidism & 2.9 \\
Hepatitis & 3.3 \\
Adrenal Insufficiency & 4.3 \\
Diabetes Mellitus Type 1 & 4.4 \\
Nephritis/Renal Dysfunction & 4.6 \\
Hypophysitis & 4.9 \\
Colitis & 5.3 \\
Encephalitis & 7.2 \\
\hline
\end{tabular}

study, and a small trial indicate overall safety and may, in fact, be an avenue for future treatment. ${ }^{29-34}$ However, data are currently limited for both patients with chronic infection and autoimmune disorders and more study is warranted. ${ }^{25}$

Treatment of these side effects is multifaceted. The family physician should feel empowered to treat moderate to severe side effects with an initial dose of $1 \mathrm{mg} / \mathrm{kg} /$ day to $2 \mathrm{mg} / \mathrm{kg} /$ day prednisone or equivalent to withhold the offending agent, and it is the opinion of these authors to quickly refer the patient, to their oncologist for possible additional immunosuppressives. ${ }^{18-22,25}$ Most side effects have a median length of steroid treatment of only a few weeks (lowest median treatment is 5 days for hepatitis is pembrolizumab and mild-to-moderate colitis in nivolumab) to multiple months in severe cases (grade 3 to 4 colitis in ipilimumab was 4.7 months). ${ }^{18-21}$ Some side-effects will require additional treatment that is well within the purview of the family physician, such as immune-mediated hypothyroidism that may require thyroid replacement until its resolution. However, for some ongoing side effects, a referral to the system-appropriate specialist may be appropriate. ${ }^{25}$ For example, if the patient acquires persistent immune-mediated colitis, a referral to a gastroenterologist may be warranted. Clinical judgment must be used on a caseby-case basis.

\section{CAR T-cells}

CAR T-cells are T-cells which undergo genetic engineering to express a particular antigen receptor, thus allowing for major histocompatibility complex-independent activation. ${ }^{35}$ To create them, Tcells are harvested from a patient's blood by using leukapheresis, making each dose of CAR T-cells specific to each individual. ${ }^{36,37}$ The harvested cells then undergo purification and activation, most frequently via beads coated in CD $3 .{ }^{37}$ During the activation process, viral vectors carrying the anti- 
Figure 2. Flowchart of the Chimeric Antigen Receptor (CAR) T-Cell Process.

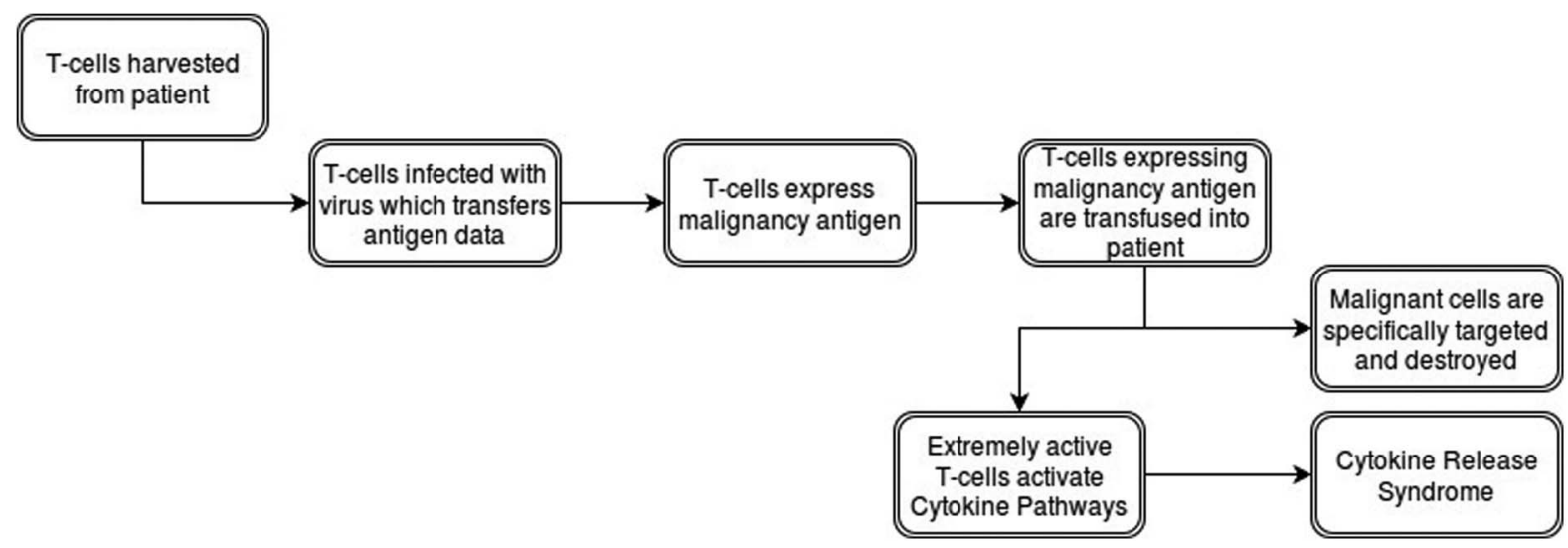

gen receptor DNA incubate with the T-cells. ${ }^{37}$ These viruses infect and transfer the information into the DNA of the host T-cell, where it becomes expressed. ${ }^{37}$ Thus, these new CAR T-cells target any cell expressing the particular antigen.

Testing these new technologies on hematologic malignancies gained traction recently, as they demonstrated very positive results treating chronic lymphocytic leukemia, acute lymphoblastic leukemia, non-Hodgkin's lymphoma, and Hodgkin's lymphoma by targeting CD19, CD20, or CD $30 .{ }^{38-48}$ Some of the most striking successes to date involve the treatment of acute lymphoblastic leukemia targeting CD19 with an initial complete remission rate of $93 \% .^{45}$ However, equally powerful to the results are its side effects. Once in a patient, CAR T-cells work rapidly, activating the cytokine pathways; this produces the so-called cytokine release syndrome (CRS). ${ }^{49}$ These symptoms include fever, fatigue, headache, seizure, nausea, rigors, chills, myalgias, dyspnea, acute respiratory distress syndrome, hypotension, acute vascular leak syndrome, tachycardia, liver function impairment, and renal failure. ${ }^{49}$ Symptoms of CRS range from mild to severe, where it becomes a cytokine storm. ${ }^{49}$ Twothirds of patients treated with CAR T-cells experience some level of CRS, sometimes very early; however, the average time frame is 6 days to 20 days after infusion. ${ }^{49-52}$ In addition, the severity of CRS may correlate with higher cancer burden at the time of treatment. ${ }^{51,53}$ To mitigate these risks, regular monitoring of cytokine levels and prompt treatment with corticosteroids and cytokine antagonists remain the standard of care. ${ }^{49,53,54}$ Further research continues to uncover ways to make CAR T-cells safer and more effective, and until this re- search is completed, the number of patients using these treatments will be limited. Figure 2 provides a visual overview of the CAR T-cell process.

\section{Neoantigens}

Neoantigens, similar to tumor-associated antigens described above, are antigens expressed only by the malignant cells secondary to mutations. These antigens, which have been demonstrated to be sometimes immunogenic, often do not add to pathology, but instead generate randomly due to disregulation of the cell cycle, which is typical of malignancy. ${ }^{55,56}$ The historic barrier to this approach arose from the need to find and typify these antigens, a process too cumbersome to perform until recent advancements in DNA sequencing. ${ }^{55}$ Now, the prediction of differences of expressed proteins can be made by sequencing and comparing the exomes of both the patient's native cells and the malignant cells. ${ }^{55}$ This process creates an extremely personalized set of antigens that become the basis for a vaccine. This vaccine induces an immune response against the tumor, while sparing the nonmalignant tissue. ${ }^{56}$ Currently, data from preclinical trials suggest a treatment response and clinical trials are underway, some of which are targeting melanomas. ${ }^{57-60}$ This treatment strategy is still in early development and, therefore, side effects are yet unknown. For this same reason, it is unlikely that family physicians will encounter patients in these treatments; however, it has been included here for completeness and to present the current state of immuno-oncology.

\section{Conclusions}

Immunotherapies for malignancies are an expanding area of practice, with a dramatic increase in the 
number of patients who receive them. Thus, it is beneficial for the family physician to be conscious of the side effect profiles of the various classes. Checkpoint inhibitors possess autoimmune side effects such as pneumonitis, hypothyroidism, and colitis. These may present at any time the patient is on the medications but are more common several weeks to several months after beginning therapy. CAR T-cell therapies are being pursued at several centers across the country. They are powerful but have strong side effects such as CRS. Neoantigens are currently in the early stages of clinical trials and may become an exciting avenue for personalized cancer treatment but are not yet typical.

To see this article online, please go to: http://jabfm.org/content/ 31/4/620.full.

\section{References}

1. Jessy T. Immunity over inability: the spontaneous regression of cancer. J Nat Sci Biol Med 2011;2: 43-9.

2. Wiemann B, Starnes CO. Coley's toxins, tumor necrosis factor and cancer research: a historical perspective. Pharmacol Ther 1994;64:529-64.

3. Coley WB. The treatment of malignant tumors by repeated inoculations of erysipelas. With a report of ten original cases. 1893. Clin Orthop Relat Res 1991; 262:3-11.

4. Parish CR. Cancer immunotherapy: the past, the present and the future. Immunol Cell Biol 2003;81: 106-13.

5. Burnet FM, Fenner F, eds. The production of antibodies. London: Macmillan and Company, 1949.

6. Verma S, Miles D, Gianni L, et al. Trastuzumab emtansine for HER2-positive advanced breast cancer. N Engl J Med 2012;367:1783-91.

7. Burnet FM. Immunological aspects of malignant disease. Lancet 1967;1:1171-4.

8. Ishida Y, Agata Y, Shibahara K, Honjo T. Induced expression of PD-1, a novel member of the immunoglobulin gene superfamily, upon programmed cell death. EMBO J 1992;11:3887-95.

9. Brunet JF, Denizot F, et al. A new member of the immunoglobulin superfamily-CTLA-4. Nature 1987;328:267-70.

10. Bretscher P, Cohn M. A theory of self-nonself discrimination. Science 1970;169:1042-9.

11. Coyle AJ, Gutierrez-Ramos JC. The expanding B7 superfamily: increasing complexity in costimulatory signals regulating $\mathrm{T}$ cell function. Nat Immunol 2001;2:203-9.

12. Gibson HM, Mishra A, Chan DV, Hake TS, Porcu $\mathrm{P}$, Wong HK. Impaired proteasome function activates GATA3 in T cells and upregulates CTLA-4: relevance for Sezary syndrome. J Invest Dermatol 2013;133:249-57.

13. Wong HK, Wilson AJ, Gibson HM, et al. Increased expression of CTLA-4 in malignant T-cells from patients with mycosis fungoides - cutaneous $\mathrm{T}$ cell lymphoma. J Invest Dermatol 2006;126:212-9.

14. Xerri L, Devilard E, Hassoun J, Olive D, Birg F. In vivo expression of the CTLA4 inhibitory receptor in malignant and reactive cells from human lymphomas. J Pathol 1997;183:182-7.

15. Kieser A, Kilger E, Gires O, Ueffing M, Kolch W, Hammerschmidt $W$. EpsteinBarr virus latent membrane protein- 1 triggers AP- 1 activity via the c-Jun N-terminal kinase cascade. EMBO J 1997; 16:6478-85.

16. Green MR, Rodig S, Juszczynski P, et al. Constitutive AP-1 activity and EBV infection induce PD-L1 in Hodgkin lymphomas and posttransplant lymphoproliferative disorders: implications for targeted therapy. Clin Cancer Res 2012;18:1611-8.

17. Kataoka K, Shiraishi Y, Takeda Y, et al. Aberrant PD-L1 expression through 3'-UTR disruption in multiple cancers. Nature 2016;534:402-6.

18. Yervoy (ipilimumab) Injection, prescribing information. Princeton, N.J: Bristol-Myers Squibb. Available at: https://packageinserts.bms.com/pi/pi_yervoy. pdf. Published 2017. Accessed March 10, 2018.

19. Opdivo (nivolumab) Injection, prescribing information. Princeton, N.J: Bristol-Myers Squibb. Available at: https://packageinserts.bms.com/pi/pi_opdivo. pdf. Published 2017. Accessed March 10, 2018.

20. Keytruda (Pembrolizumab) Injection, prescribing information. Whitehouse Station, N.J: Merck and Co., Inc. Available at: http://www.keytruda.com/ hcp/. Published 2017. Accessed March 10, 2018.

21. Tecentriq (atezolizumab) Injection, prescribing information. South San Francisco, C.A: Genentech, Inc. Available at: http://www.tecentriq.com/hcp. html. Published 2017. Accessed March 10, 2018.

22. Bavencio (avelumab) Injection, prescribing information. Darmstadt, Germany: EMD Serono, Inc. Available at: http://medical.emdserono.com/content/ dam/web/health-care/biopharma/web/USMI/ Forms/Bavencio_PI_UC.pdf. Published May 2017. Accessed March 11, 2018.

23. Reck M, Rodriguez-Aubreu D, Robinson AG, et al. Pembrolizumab versus chemotherapy for PD-L1 positive non-small-cell lung cancer. N Eng J Med 2016;375:1823-33.

24. Kourie H, Klastersky J. Immune checkpoint inhibitors side effects and management. Immunotherapy 2016;8:799-807.

25. Inno A, Metro G, Bironzo P, et al. Pathogenesis, clinical manifestations and management of immune checkpoint inhibitors toxicity. Tumori 2017;103: $405-21$.

26. Johnson D, Sullivan R, Ott P, et al. Ipilimumab therapy in patients with advanced melanoma and 
preexisting autoimmune disorders. JAMA Oncol 2016;2:234-40.

27. Bertrand A, Kostine M, Barnetche T, Truchetet ME, Schaever-beke T. Immune related adverse events associated with anti-CTLA-4 antibodies: systematic review and meta-analysis. BMC Med 2015; $13: 211.24$.

28. Menzies A, Johnson D, Ramanujam S, et al. AntiPD-1 therapy in patients with advanced melanoma and preexisting autoimmune disorders or major toxicity with ipilimumab. Ann Oncol 2016 Sep 29.

29. Sharma A, Thompson J, Repaka A, Mehnert J. Ipilimumab administration in patients with advanced melanoma and hepatitis B and C. J Clin Oncol 2013; 31:e370-e372.

30. Ravi S, Spencer K, Ruisi M, et al. Ipilimumab administration for advanced melanoma in patients with pre-existing hepatitis B or C infection: a multicenter, retrospective case series. J Immunother Cancer 2014;2:33.

31. Davar D, Wilson M, Pruckner C, Kirkwood J. PD-1 blockade in advanced melanoma in patients with hepatitis C and/or HIV. Case Rep Oncol Med 2015; 2015:737389.

32. Sangro B, Gomez-Martin C, de la Mata M, et al. A clinical trial of CTLA-4 blockade with tremelimumab in patients with hepatocellular carcinoma and chronic hepatitis C. J Hepatol 2013;59:81-8.

33. Gardiner D, Lalezari J, Lawitz E, et al. A randomized, double-blind, placebo-controlled assessment of BMS-936558, a fully human monoclonal antibody to programmed death-1 (PD-1), in patients with chronic hepatitis $\mathrm{C}$ virus infection. PLoS ONE 2013;8:e63818.

34. Rao M, Valentini D, Dodoo E, Zumla A, Maeurer M. Anti-PD-1/PD-L1 therapy for infectious diseases: learning from the cancer paradigm. Int J Infect Dis 2017;56:221-8.

35. Eshhar Z, Waks T, Gross G, Schindler DG. Specific activation and targeting of cytotoxic lymphocytes through chimeric single chains consisting of antibody-binding domains and the gamma or zeta subunits of the immunoglobulin and T-cell receptors. Proc Natl Acad Sci U S A 1993;90:720-4.

36. Smith JW. Apheresis techniques and cellular immunomodulation. Ther Apher 1997;1:203-6.

37. Levine BL, Miskin J, Wonnacott K, Keir C. Global manufacturing of CAR T cell therapy. Molecular therapy methods \& clinical development 2017;4:92101.

38. Turtle CJ, Hanafi LA, Berger C, et al. CD19 CAR-T cells of defined CD4+:CD8 + composition in adult B cell ALL patients. J Clin Invest 2016;126: 2123-38.

39. Lee DW, Kochenderfer JN, Stetler-Stevenson M, et al. T cells expressing CD19 chimeric antigen receptors for acute lymphoblastic leukaemia in children and young adults: a phase 1 dose-escalation trial. Lancet 2015;385:517-28.

40. Maude SL, Frey N, Shaw PA, et al. Chimeric antigen receptor $\mathrm{T}$ cells for sustained remissions in leukemia. N Engl J Med 2014;371:1507ra17.

41. Davila ML, Riviere I, Wang X, et al. Efficacy and toxicity management of 19-28 CAR T cell therapy in B cell acute lymphoblastic leukemia. Sci Transl Med 2014;6:224-5.

42. Turtle CJ, Hanafi LA, Berger C, et al. Immunotherapy of non-Hodgkin's lymphoma with a defined ratio of $\mathrm{CD} 8+$ and CD4+ CD19-specific chimeric antigen receptor-modified $\mathrm{T}$ cells. Sci Transl Med 2016;8:355ra116.

43. Kochenderfer JN, Dudley ME, Kassim SH, et al. Chemotherapy-refractory diffuse large B-cell lymphoma and indolent B-cell malignancies can be effectively treated with autologous $\mathrm{T}$ cells expressing an anti-CD19 chimeric antigen receptor. J Clin Oncol 2015;33:540-9.

44. Kalos M, Levine BL, Porter DL, et al. T cells with chimeric antigen receptors have potent antitumor effects and can establish memory in patients with advanced leukemia. Sci Transl Med 2011;3:95ra73.

45. Grupp SA, Maude SL, Shaw PA, et al. Durable remissions in children with relapsed/refractory ALL treated with $\mathrm{T}$ cells engineered with a CD19- targeted chimeric antigen receptor (CTL019). Blood 2015;126:681.

46. Cai B, Guo M, Wang Y, et al. Co-infusion of haploidentical CD19-chimeric antigen receptor $\mathrm{T}$ cells and stem cells achieved full donor engraftment in refractory acute lymphoblastic leukemia. J Hematol Oncol 2016;9:131.

47. Zhang W-y, Wang Y, Guo Y-l, et al. Treatment of CD20-directed chimeric antigen receptor-modified $\mathrm{T}$ cells in patients with relapsed or refractory Bcell non-Hodgkin lymphoma: an early phase IIa trial report. Signal Transduction Target Ther 2016;1: 16002.

48. Wang CM, Wu ZQ, Wang Y, et al. Autologous T cells expressing CD30 chimeric antigen receptors for relapsed or refractory Hodgkin lymphoma: an open label phase I trial. Clin Cancer Res 2017;23: 1156-66.

49. Xu X, Tang Y. Cytokine release syndrome in cancer immunotherapy with chimeric antigen receptor engineered T cells. Cancer Lett 2014;343:172-178.

50. Brentjens RJ, Yeh R, Bernal Y, Riviere I, Sadelain M. Treatment of chronic lymphocytic leukemia with genetically targeted autologous $T$ cells: case report of an unforeseen adverse event in a phase I clinical trial. Mol Ther 2010;18:666-8.

51. Morgan RA, Yang JC, Kitano M, Dudley ME, Laurencot CM, Rosenberg SA. Case report of a serious adverse event following the administration of $\mathrm{T}$ cells transduced with a chimeric antigen receptor recognizing ERBB2. Mol Ther 2010;18:843-51. 
52. Brentjens RJ, Riviere I, Park JH, et al. Safety and persistence of adoptively transferred autologous CD19- targeted $\mathrm{T}$ cells in patients with relapsed or chemotherapy refractory B-cell leukemias. Blood 2011;118:4817-28.

53. Brentjens RJ, Davila ML, Riviere I, et al. CD19-targeted $\mathrm{T}$ cells rapidly induce molecular remissions in adults with chemotherapy-refractory acute lymphoblastic leukemia. Sci Trans Med 2013;5:177-138.

54. Grupp SA, Kalos M, Barrett D, et al. Chimeric antigen receptor-modified $\mathrm{T}$ cells for acute lymphoid leukemia. N Engl J Med 2013;368:1509-18.

55. Caietto A, Jhunjhunwala S, Delamarre L. Characterizing neoantigens for personalized cancer immunotherapy. Curr Opin Immunol 2017;46:58-65.

56. Sharma P, Allison JP. The future of immune checkpoint therapy. Science 2015;348:56-61.
57. Yadav M, Jhunjhunwala S, Phung QT, et al. Predicting immunogenic tumour mutations by combining mass spectrometry and exome sequencing. Nature 2014;515:572-6.

58. Gubin MM, Zhang X, Schuster H, et al. Checkpoint blockade cancer immunotherapy targets tumour-specific mutant antigens. Nature 2014;515: 577-81.

59. Kreiter S, Vormehr M, van de Roemer N, et al. Mutant MHC class II epitopes drive therapeutic immune responses to cancer. Nature 2015;520: 692-6.

60. Carreno BM, Magrini V, Becker-Hapak M, et al. A dendritic cell vaccine increases the breadth and diversity of melanoma neoantigen-specific T cells. Science 2015;348:803-8. 